\title{
Does Pre-Admissions Testing Play a Role in Math Performance Among Students Enrolled in a 2-Year Practical Nursing Diploma Program?
}

\author{
Dalya Abdulla (Corresponding author) \\ Sheridan College Institute of Technology and Advanced Learning \\ 7899 McLaughlin Road, Brampton, ON, L6Y 5H9, Canada \\ Tel: 1-905-459-7533 E-mail: dalya.abdulla@sheridanc.on.ca \\ Paul Jeffrey \\ Humber College, 205 Humber College Blvd. \\ Toronto, ON, M9W 5L7, Canada \\ Tel: 416-675-6622Ｅ-mail: paul.jeffrey@humber.ca
}

Received: April 18, 2014 Accepted: May 4, 2014 Published: May 18, 2014

doi:10.5296/jet.v1i2.5495 URL: http://dx.doi.org/10.5296/jet.v1i2.5495

\begin{abstract}
Pre-admissions tests are typically used to supplement student selection in health care professional programs and therefore the objective of this study was to determine the potential role of pre-admissions testing on Practical Nursing student performance in college level pharmaceutical calculations. The pre-admissions test selected by Sheridan College was the HOAE (Health Occupation Aptitude Examination) exam, and math performance was measured using objective endpoints from two courses that students enrol in within their first and second semesters within the program. Results from both semesters revealed a minimal role for pre-admissions testing on math performance among accepted students. This indicates that student selection decisions should not be solely based on pre-admissions tests and should be augmented with mini-interviews or the requirement of completing a pre-professional semester prior to entry into the program.
\end{abstract}

Keywords: Pre-admissions Testing, Student Performance, Math Skills, 2-Year Diploma, Practical Nursing 


\section{Introduction}

The utilization of appropriate candidate selection methods allows the admission of students who have the highest chance of success both within the context of the program and following graduation as clinical practitioners (Kogan \& McConnell, 2001; Rich et al., 2012; Salvatori, 2001). To this extent, pre-admissions tests have been used as student selection tools, either solely or as a supplementary method, due to their ability to introduce transparency in the admissions process and reasonably predict student performance beyond the first year of college (Edwards, Coates, \& Friedman, 2012; Saupe \& Eimers, 2011). Additional benefits of pre-admissions testing include the introduction of objectivity, efficiency, and accuracy in the student selection process, thereby reducing the impacts of secondary school assessment inconsistencies in the admissions process (Edwards et al., 2012).

Pre-admissions testing was implemented at the Faculty of Applied Health and Community Studies (FAHCS) at Sheridan College during the Fall 2011 semester in an effort to enhance the pool of students accepted into the 2-year Practical Nursing (PN) diploma program. The selected pre-admissions test was the HOAE exam (Health Occupation Aptitude Examination), a multiple choice examination that assesses student's skill and aptitude in English, math, critical thinking, and problem solving. Since past academic achievement in math and verbal ability are typically indicative of future college performance (Marnewick, 2012; Schmitt, 2012), these two topics were selected as the two essential components to be included in the HOAE test utilized by FAHCS at Sheridan College. The test is heavily utilized by many Colleges in Ontario as an entrance criterion for admissions into College-level Health Professional Programs. Additional information on this test can be obtained from the link: http://www.psbtests.com/web/guest/home.

Despite their influence on student selection in health sciences programs, research on pre-admissions testing is fairly limited (Edwards et al., 2012); studies looking at the impacts of pre-admissions tests on 2-year college programs are even more scarce. Since PN math knowledge must be associated with a zero tolerance for error (Abdulla, 2012; Bourne \& Davison, 2006), the main objective of this study was to determine the role of pre-admissions testing on student ability, aptitude, and achievement in math skills and knowledge in the PN program during Pharmacy Math (MATH16532, a first semester course) and Pharmacology for Nurses I (PHAR15288, a second semester course). Math concepts are typically revisited in upper semester courses in the PN program to ensure students continue revising and refining their skills as they progress through the program, especially since the ability to perform pharmaceutical calculations accurately will drive safer nursing practices among graduates and will aid them in their clinical reasoning processes.

\section{Theoretical Background}

Student selection into health related programs has always been a challenge, especially with potentially qualified applicants exceeding the available spaces in the program (Kogan \& McConnell, 2001; Salvatori, 2001; Vargo, Madill, \& Davidson, 1986). The competitive nature of such programs requires selectivity in accepted students; selection committees in educational institutions must therefore take the onus to select students who will maximize 
their college experience and attain the greatest potential within their selected profession (Edwards et al., 2012; Kogan \& McConnell, 2001; Sternberg, Gabora, \& Bonney, 2012). This is especially true in nursing programs, where the number of applicants to nursing programs far exceeds the available seats each semester: at Sheridan College, approximately 1000-1500 potential applications are received in any given semester for the PN program at Sheridan College yet only 50-70 seats are available per semester. It therefore becomes imperative to select only the "best" candidates into the PN program at Sheridan College by utilizing appropriate selection tools and criteria.

Health professional programs select the "best" candidates based on Grade Point Average (GPA) in addition to factors such as volunteer/paid work in the area, personal interview performance, personal statements, academic achievement test results, and references; this ultimately allows the selection of candidates most likely to succeed both within the program and following program completion based on clinical competence (Edwards et al., 2012; Pelech, Stalker, Regehr, \& Jacobs, 1999; Rich et al., 2012; Salvatori, 2001). Appropriate student selection methods will allow the evaluation of clinical reasoning skills among applicants, a skill that is essential for future nurses and health care practitioners. Accurate student selection will also reduce the demands placed on staff and faculty dealing with students who are potentially "struggling" within the program, including those unable to perform in a field placement, failing to complete course requirements, and exhibiting difficulty in interpersonal relationships (Pelech et al., 1999).

The sole reliance of selection committees on academic performance has been shown to be insufficient in determining logical reasoning, problem solving skills, and student motivation among students accepted into any given program (Rich et al., 2012). To that measure, pre-admission tests can introduce transparency in the admissions process and facilitate a reasonable prediction of student performance beyond the first year of college (Edwards et al., 2012; Saupe \& Eimers, 2011). Such tests also reduce the impacts of secondary school assessment inconsistencies in the admissions process and can impart cost-savings for the program as a whole, since they can decrease the amount of students dropping out of the program (Edwards et al., 2012; Reibnegger et al., 2010). This imparts a substantial advantage to the administration of educational institutions, since student retention tends to be a major challenge in many programs. Pre-admissions tests can measure student aptitude and potential to acquire knowledge, allowing health professional schools to select students who are most likely to succeed in the program and as future practitioners (Geiser, 2009; Stemler, 2012). It is critical though that the selected pre-admissions test be subject-specific or locally developed as tests of a broad nature have been shown to be influenced by socioeconomic standing, parental experiences, and access to test preparatory material (Geiser, 2009; Lai et al., 2008; Mattimore, 2008; McDermott, 2008; Morrison \& Schmit, 2010; Schultz \& Austin, 1987).

\section{Research Questions}

Due to the critical role that student selection methods play in student future performance in the program, this study considered the impacts of pre-admissions testing on student math performance in the PN program. In this study, performance refers to the ability of students to 
answer questions based on knowledge repetition, ability to apply their knowledge, and ability to critically analyze their knowledge to answer the questions. Math performance was utilized as an endpoint since students in health care professions must exhibit a $100 \%$ proficiency level in pharmaceutical calculations. The research in this study was therefore based on the following two questions:

1) What role, if any, does pre-admissions testing play in student performance of pharmaceutical calculations during their first semester within the PN program?

2) Does pre-admissions testing impact student performance of pharmaceutical calculations when students progress to the second semester of the PN program?

\section{Methods}

\subsection{Pre-Admissions Test Information}

The Practical Nursing Program at Sheridan College is a 2-year diploma program (divided into four semesters) that prepares students for a career as a registered PN. During the program students are introduced to topics such as Fundamentals of Practical Nursing, Self and Profession, Anatomy and Disease Conditions, Pharmacology, Health Assessment, Realities of Practice, Family Care Nursing, and Mental Health Nursing. Current admission standards in the PN program require that students score a minimum of $65 \%$ (numeric score of 199 out of 305 ) in the HOAE test and complete 4 secondary level courses: Grade 12 English, Grade 12 College or University Mathematics, Grade 11 College or University Biology, and Grade 12 College or University Chemistry (or Grade 11 University Chemistry). The student's secondary level high school GPA (Grade Point Average) plays an important role in the application and acceptance process and is calculated from the above four core courses along with the grades from two other higher level senior courses taken by the student. Once the student possesses the minimum application requirements, the College creates a combined score for the potential applicant that is based, in equal weight, on the GPA and the HOAE score. An offer of admission into the PN program is extended to the student only if their combined score (based on GPA and the HOAE test score) exceeds 70\%. Prior to the implementation of pre-admissions testing, student acceptance into the PN program was based solely on the student's secondary level high school GPA.

\subsection{Student Sample}

Utilizing a longitudinal study design, participants consisted of all students registered in the first and second semesters within the PN program at Sheridan College. Student grades in the Midterm and Final exams from four different MATH16532 sections were analyzed for the prior to pre-admissions testing group. All four sections consisted of students enrolled in their first semester of the PN program during the Fall (September - December) 2010 term with an average number of 24 students for this group. A total of 4 sections from the Fall (September - December) 2011 term were analyzed to obtain results for student performance in MATH16532 in the after pre-admissions testing group. The average number of students for this result group was 25 students. After completing MATH16532 in their first semester, students enroll in PHAR15288 (Pharmacology for Nurses I) in the second semester of the 
program where their knowledge of math is also reviewed in the form of mathematical skill questions embedded in the course examinations. Results for students who did not write the pre-admissions test were obtained from one PHAR15288 section containing 40 students in the Fall (September - December) 2011 term. Two sections of PHAR15288 from the Winter (January - April) 2012 term were utilized to obtain results for students results who wrote the pre-admissions test with an average number of 40 students for both sections.

\subsection{Math Content and Assessment Description}

MATH16532 consists of a Midterm and Final examination worth 30\% and 35\%, respectively, of the course grade; course content is based on oral, parenteral, and intravenous (IV) dosage calculations. The Midterm examination typically covers oral dosage calculations and unit conversions and consists of 25-35 multiple choice questions, with 1.5-3 minutes provided per question. The Final examination is comprehensive and consists of $40-50$ questions with a similar format to the Midterm examination. A total of up to 5 bonus questions are incorporated in each examination (Midterm and Final). PHAR15288 contains a Midterm examination worth $20 \%$ of the final grade and a Final examination worth $30 \%$ of the grade. Both examinations consist of multiple choice questions and students are provided with an average of 1.5 minutes per question for both examinations. Up to 5 math skill questions are usually incorporated in both examinations, with content based on oral, parenteral, and IV dosages along with unit conversions and dosage interpretations. The types of pharmaceutical calculation questions in both courses were comparable, with questions derived from three main categories: direct knowledge, application-type questions, and questions requiring critical thinking cells. Sample questions are provided in Table 1. All multiple choice questions provided students with four potential answers, and students had to select the most appropriate answer as the correct response. Students were subjected to no penalties for answering questions incorrectly and the grade for each assessment was numerically calculated based on number of questions answered correctly.

\subsection{Statistical Analysis}

Results from the student assessments in each MATH16532 section are provided as percentages of the total student scores for that specific section and grade range. Similarly, second semester student results are provided as percentages of the number of students per section who answered each math skill question either correctly or incorrectly within each question subgroupings (Oral Dosage Calculations, Parenteral Dosage Calculations, IV Dosage Calculations, and Unit Conversions and Dosage Interpretations). Unpaired t-tests were used to analyze student performance for each grade range (sample size of 4 for each group) with the level of significance set at 5\%. Average results from all sections are presented in one graph for illustrative purposes, with white bars representing results for the prior to pre-admissions testing group and black bars representing results from the after pre-admissions testing group. 


\section{Ml Macrothink}

Table 1. Sample Pharmaceutical Calculation Questions

\begin{tabular}{|c|c|}
\hline Category & Question Sample \\
\hline $\begin{array}{l}\text { Oral } \\
\text { Dosages } \\
\text { (direct } \\
\text { knowledge } \\
\text { question) }\end{array}$ & $\begin{array}{l}\text { How many tablets should be administered per dose? } \\
\text { Order: gr } 1 / 4 \text { TID } \\
\text { Supply: tablets of } 15 \mathrm{mg} \text { per tablet (scored) } \\
\text { a. } \quad \mathbf{1} \text { tablet } \\
\text { b. } \quad 2 \text { tablets } \\
\text { c. } \quad 3 \text { tablets } \\
\text { d. } \quad 4 \text { tablets }\end{array}$ \\
\hline $\begin{array}{l}\text { Parenteral } \\
\text { Dosages } \\
\text { (critical } \\
\text { analysis } \\
\text { question) }\end{array}$ & $\begin{array}{l}\text { Determine how much volume should be administered per dose } \\
\text { based on the following scenario: } \\
\text { Order: Pfizerpen (penicillin G potassium) } 600,000 \text { I.U. } \\
\text { (International Units) IM } \\
\text { Supply: Pfizerpen (penicillin G potassium) dry powder } 5 \text { million } \\
\text { I.U. } \\
\text { Reconstitution: add } 18.2 \mathrm{~mL} \text { to the vial containing Pfizerpen dry } \\
\text { powder to obtain a final concentration of } 250,000 \text { I.U. } / \mathrm{mL} \\
\text { a. } \quad 8.3 \mathrm{~mL} \\
\text { b. } \quad 5 \mathrm{~mL} \\
\text { c. } \quad 3.3 \mathrm{~mL} \\
\text { d. } \quad \mathbf{2 . 4} \mathbf{~}\end{array}$ \\
\hline $\begin{array}{l}\text { Intravenous } \\
\text { Dosages } \\
\text { (application } \\
\text { question) }\end{array}$ & $\begin{array}{l}\text { The order is for } 1830 \mathrm{~mL} \text { D } 5 \mathrm{~W} \text { IV to be infused at a drop factor } \\
\text { of } 20 \mathrm{gtt} / \mathrm{mL} \text { and a flow rate of } 60 \mathrm{gtt} / \mathrm{min} \text {. How long will it take } \\
\text { for this IV infusion to infuse in minutes? } \\
\text { a. } 61 \mathrm{~min} \\
\text { b. } \quad 610 \mathrm{~min} \\
\text { c. } \quad 600 \mathrm{~min} \\
\text { d. } \quad 60 \mathrm{~min}\end{array}$ \\
\hline
\end{tabular}

Sample questions used in MATH16532 and PHAR15288 Assessments to determine student performance (correct answers provided in bold font).

\section{Impacts of Pre-Admissions Testing}

\subsection{Role of Pre-Admissions Testing on Student Demographics}

Prior to pre-admissions testing, the percentage of male students accepted into the PN program at Sheridan College was 33\% $\pm 19 \%$ compared to $67 \% \pm 19 \%$ accepted female students. A similar result was observed in the student group accepted into the PN program following the implementation of pre-admissions testing: $29 \% \pm 9 \%$ male students versus $71 \% \pm 9 \%$ female students. Even though a statistically significant component of candidates accepted into the PN program tended to be females, no significant gender differences were observed between the prior to and post pre-admissions testing groups. Pre-admissions testing also did not impact the age of students accepted into the PN program: prior to pre-admissions testing, the percentages of students in the $<25$ years, 25-35 years, and $>35$ years age ranges were $49 \% \pm$ $14 \%, 36 \% \pm 10 \%$, and $14 \% \pm 11 \%$, respectively, while after pre-admissions testing, these 
percentages in the age same groups were $61 \% \pm 17 \%, 32 \% \pm 10 \%$, and $16 \% \pm 7 \%$, respectively.

\subsection{Student Performance in Math}

Student grades from first semester student performance in MATH16523 were grouped in ranges of $<50 \%, 50-69.9 \%, 70-90 \%$, and $>90 \%$. The percentage of students scoring within each range for each of the Midterm examination, Final examination, and the MATH16532 course as a whole are presented in Figure 1.

(A) Midterm Exam Results

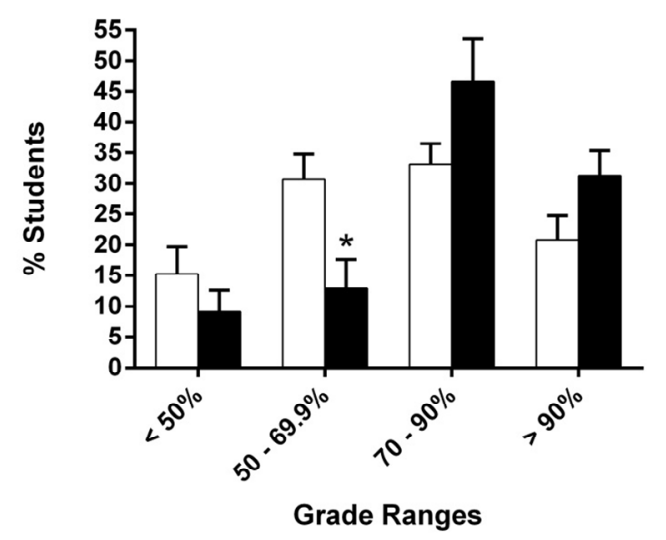

(C) Final Course

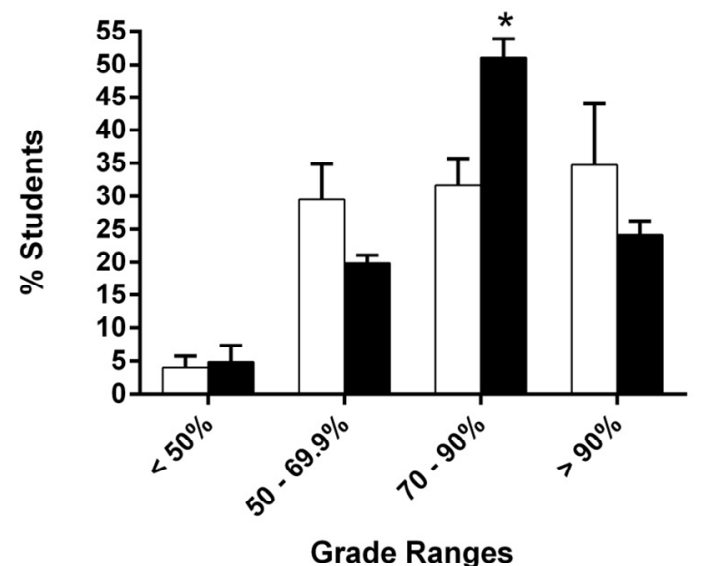

(B) Final Exam

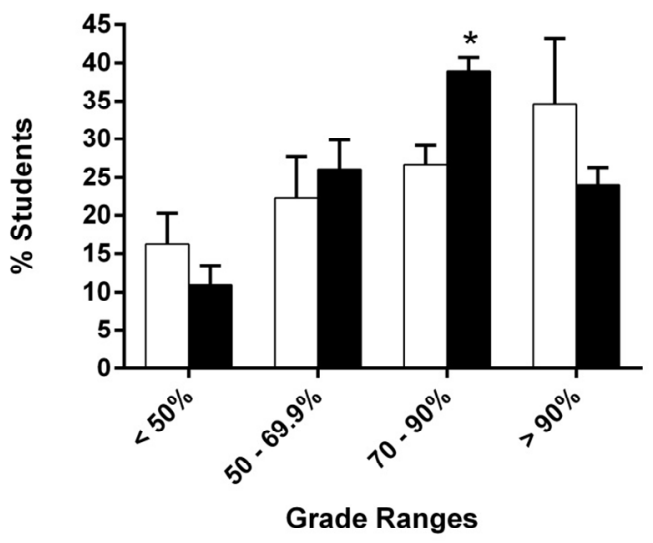

Figure 1. The Impacts of Pre-Admissions Testing on Course Grades in MATH16532

Figure 1 Legend: The impacts of pre-admissions testing were determined on student performance in the Midterm examination (A), Final examination (B), and Course Grades as whole $(\mathrm{C})$. Results are presented for the four different grade ranges for each assessment. * represents a statistically significant result $(\mathrm{P}<0.05)$ in the "After Pre-Admissions Testing" group compared to "Prior Pre-Admissions Testing" group using an unpaired t-test. White bars represent results for the prior to pre-admissions testing group while black bars represent results from the after pre-admissions testing group. 
Four basic level questions were embedded in the Midterm and Final examinations of PHAR15288 to assess second semester student knowledge on Unit Conversions and Dosage Interpretation. Pre-admissions testing had a minimal impact on two of the questions in this group, both administered during the midterm examination. In the remaining two questions in the Unit Conversions and Dosage Interpretation group, both administered during the Final examination, moderate increases were observed in terms of the number of students who answered the questions correctly in the pre-admissions testing group compared to those who did not write the test. Two questions were employed to test student knowledge in Oral Dosage Calculations, with both questions provided in the Midterm examination. The first question required basic dosage identification and the number of students who responded correctly to this question was lower among the pre-admissions testing group compared to those who did not take the pre-admissions test. The second question required the student to identify the correct units before performing the actual dosage calculation and in this question, a higher number of students who wrote the pre-admissions testing answered this question correctly compared to the group who did not write the pre-admissions test. Students were also required to answer two Parenteral Dosage Calculation questions, one in the Midterm and the other in the Final examination. The first question was a basic dosage calculation and was administered in the Midterm examination; a higher number of correct responses was observed to this question among students who wrote the pre-admissions test compared to those who did not write the test. The second Parenteral Dosage Calculation question was administered in the Final examination and provided students with additional non-required information and students had to select the required variables to solve the question; in this question, a small increase in correct responses was observed among students who wrote the pre-admissions test compared to those who did not write the test. More consistent increases in correct responses to IV Dosage Calculation questions were observed among students who wrote the pre-admissions test compared to those who did not write the test. All three IV Dosage Calculation questions were embedded in the Final examination and were based on advanced IV topics such as calculation of elapsed infusion time and determination of complex flow rates. A summary of these results in provided in Table 2. 
Table 2. Second semester student performance

\begin{tabular}{|c|c|c|c|c|}
\hline & & $\begin{array}{c}\text { Question } \\
\text { Description }\end{array}$ & $\begin{array}{c}\text { \% Correct } \\
\text { Responses Prior to } \\
\text { Pre-Admissions } \\
\text { Testing } \\
\end{array}$ & $\begin{array}{c}\text { \% Correct } \\
\text { Responses After } \\
\text { Pre-Admissions } \\
\text { Testing }\end{array}$ \\
\hline \multirow{4}{*}{$\begin{array}{l}\text { Unit Conversions } \\
\text { and Dosage } \\
\text { Interpretations }\end{array}$} & Midterm & $\begin{array}{l}\text { Basic Unit } \\
\text { Conversion }\end{array}$ & $92.5 \%$ & $91.5 \%$ \\
\hline & Midterm & $\begin{array}{l}\text { Basic Dosage } \\
\text { Interpretation }\end{array}$ & $95.0 \%$ & $94.5 \%$ \\
\hline & Final & $\begin{array}{l}\text { Basic Unit } \\
\text { Conversion }\end{array}$ & $75.0 \%$ & $91.3 \%$ \\
\hline & Final & $\begin{array}{l}\text { Basic Dosage } \\
\text { Interpretation }\end{array}$ & $67.5 \%$ & $81.1 \%$ \\
\hline \multirow{2}{*}{$\begin{array}{l}\text { Oral Dosage } \\
\text { Calculations }\end{array}$} & Midterm & $\begin{array}{l}\text { Basic Oral } \\
\text { Dosage } \\
\text { Calculation }\end{array}$ & $95.0 \%$ & $89.7 \%$ \\
\hline & Midterm & $\begin{array}{c}\text { Analytical Oral } \\
\text { Dosage } \\
\text { Calculation }\end{array}$ & $67.5 \%$ & $87.5 \%$ \\
\hline \multirow{2}{*}{$\begin{array}{c}\text { Parenteral } \\
\text { Dosage } \\
\text { Calculations }\end{array}$} & Midterm & $\begin{array}{c}\text { Basic } \\
\text { Parenteral } \\
\text { Dosage } \\
\text { Calculation }\end{array}$ & $77.5 \%$ & $90.8 \%$ \\
\hline & Final & $\begin{array}{l}\text { Analytical } \\
\text { Parenteral } \\
\text { Dosage } \\
\text { Calculation }\end{array}$ & $82.5 \%$ & $85.1 \%$ \\
\hline \multirow{3}{*}{$\begin{array}{c}\text { IV Dosage } \\
\text { Calculations }\end{array}$} & Final & $\begin{array}{l}\text { Advanced IV } \\
\text { Dosage } \\
\text { Calculation } \\
\end{array}$ & $82.5 \%$ & $89.8 \%$ \\
\hline & Final & $\begin{array}{l}\text { Advanced IV } \\
\text { Dosage } \\
\text { Calculation }\end{array}$ & $80.0 \%$ & $87.7 \%$ \\
\hline & Final & $\begin{array}{l}\text { Advanced IV } \\
\text { Dosage } \\
\text { Calculation }\end{array}$ & $62.5 \%$ & $72.2 \%$ \\
\hline
\end{tabular}

Performance of second semester students in math skills questions embedded in PHAR15288 (Introduction to Pharmacology). 


\section{Discussion}

Prior to the Fall 2011 semester, student acceptance into the Practical Nursing program at Sheridan College was based on high school performance in several core preparatory courses, with academic performance playing a major determining factor into acceptance into the PN program. Due to the importance of determining student problem solving abilities and both logical and clinical reasoning skills, the HOAE test was implemented during the Fall 2011 semester to assess these two skills in the aim of admitting a higher calibre of students into the program. Based on the results of this study, pre-admissions testing did not influence the numbers of potential applicants to the PN program, with an average of 1132 students applying to the program regardless of the pre-admissions test requirement. Additionally, pre-admissions testing had no impact on age and gender of students accepted into the program.

Maintaining an accurate math skill set is essential for students accepted into health care programs, since studies have shown that students admitted into college are not prepared to use or apply mathematics in introductory science courses (Wenner, Burn, \& Baer, 2011). An additional stringency is that PN students at Sheridan College are expected to display a "zero tolerance" attitude towards pharmaceutical calculation errors. Such an attitude will impact performance in their nursing practice, especially in light of the PN's expanded scope of practice (C.N.O., 2012). The PN program at Sheridan College typically receives a large number of applicants and therefore the HOAE pre-admissions test was selected as a method to attempt to accept only the "best" candidates into the program who would excel in performing pharmaceutical calculations within the program. Results of this study however indicated that pre-admissions testing had a minimal role student performance in pharmaceutical calculations.

In response to the first research question, perhaps the only major influence of pre-admissions testing was observed during the Midterm examination: a lower proportion of students scored grades in the $50-69.9 \%$ range (and correspondingly a higher proportion of students scored grades greater than $70 \%$ ) in the examination as a result of writing the pre-admissions test compared to the group who did not take the pre-admissions test. Minor changes were also observed in student grades during the Final examination and the course grade comparisons in the before and after pre-admissions testing groups. To ensure objectivity and measurability, the endpoints selected for evaluation from the first semester MATH16532 course were the Midterm examination, Final examination, and course as a whole grades. To test the second research question on whether pre-admissions testing played a role in math performance as the student progresses into the second semester of the program, several math skill questions were embedded into the second semester PHAR15288 course. Once again, the results illustrated a minimal role of pre-admissions testing, with the most consistent improvement observed in IV dosage calculations. Students are heavily exposed to IV calculations during their clinical laboratory courses in the second semester of the PN program, since these tend to be identified as the most challenging types of calculations by students during their training. It is therefore possible that the "review" of such calculations may be responsible for the minor improvements in mathematical calculation skills that were observed in this study among 
second semester students, further supporting the minimal role of pre-admissions testing in improving math skill and performance as students progress into the second semester of the program.

Results of this study illustrate that the use of the HOAE pre-admissions test offers minimal advantages when used as a method to improve math skill and performance among students accepted into the PN program. The sole use of pre-admissions testing therefore as a method to determine improvement in math skill and performance among accepted students in the PN program is not sufficient and must be augmented by other methods. Even though only two courses were used to reach this conclusion, the results of this study are in line with literature observations on the usability of pre-admissions tests as predictors of student performance (Geiser, 2009; Lai et al., 2008; Mattimore, 2008; McDermott, 2008; Morrison \& Schmit, 2010; Schultz \& Austin, 1987). Due to the essential role that math skills play in the PN program, additional alternatives and augmenters to pre-admissions testing must be sought out to enhance this student skill while in the program. Studies have shown a positive correlation between graduation GPA and performance in a pre-professional university year completed prior to program entry (Abidin, Suliman, Din, \& Manan, 2012; Geiser, 2009; Salvatori, 2001; Vargo et al., 1986). Sheridan College offers a variety of one-year General Arts \& Sciences (GAS) programs in various profiles, including College, University, Pre-Business, Technology, and Health streams. It may be of value therefore for the PN program to require potential applicants to successfully complete one semester or year of a relevant GAS program prior to applying into the program. Mini-interviews have also been shown to provide robust results in candidate selection compared to personal interviews (Cameron \& Mackeigan, 2012; Pandey \& Dixit, 2011; Salvatori, 2001; Vargo et al., 1986) and can offer faculty the chance to interact with the potential student applicants and provide feedback regarding the appropriateness of the student's choice to pursue a diploma in Nursing. Results of this study may also be extrapolated to educational institutions offering nursing diploma and undergraduate programs: pre-admissions testing tends not to be a reliable method to predict student performance in pharmaceutical calculations and must be augmented with other means to ensure students graduate from such programs with the required skill set that will enable them to practice nursing safely and accurately.

\section{Conclusion}

The aim of this study was to consider the potential impacts of implementing a pre-admissions test on student performance in math in a 2-year PN program. Based on the results of this study, pre-admissions testing was observed to play a minimal role on student performance in math calculations within a 2-year college level PN program. Appropriate student selection processes are important in ensuring the admission of a higher student calibre into a college level PN program and therefore should be employed by Admissions Committees during candidate selection.

\section{References}

Abdulla, D. (2012). Attitudes of college students enrolled in 2-year health care programs towards online learning. Computers \& Education, 59(4), 1215-1223. 
http://dx.doi.org/10.1016/j.compedu.2012.06.006

Abidin, B., Suliman, N. A., Din, S. M., \& Manan, N. A. (2012). Pre-Admissions Grades and Student Performance: The Malaysian Medical School Experience. The Clute Institute, 5(3), 145-152.

Bourne, D. W., \& Davison, A. M. (2006). A self-paced course in pharmaceutical mathematics using web-based databases. American Journal of Pharmaceutical Education, 70(5), 116.

C.N.O. (2012). RN and RPN Practice: The Client, the Nurse and the Environment, Pub. no. 41062. Retrieved from http://www.cno.org/Global/docs/prac/41062.pdf

Cameron, A. J., \& Mackeigan, L. D. (2012). Development and pilot testing of a multiple mini-interview for admission to a pharmacy degree program. Am J Pharm Educ, 76(1), 10. http://dx.doi.org/10.5688/ajpe76110

Edwards, D., Coates, H., \& Friedman, T. (2012). A Survey of International Practice in University Admissions Testing. Higher Education Management and Policy, 24(1), 87-104. http://dx.doi.org/10.1787/17269822

Geiser, S. (2009). Back to the Basics: In Defense of Achievement (and Achievement Tests) in College Admissions. Change: The Magazine of Higher Learning, 41(1), 16-23.

Kogan, L. R., \& McConnell, S. L. (2001). Gaining acceptance into veterinary school: a review of medical and veterinary admissions policies. $J$ Vet Med Educ, 28(3), 101-110.

Lai, K., Nankervis, S., Story, M., Hodgson, W., Lewenberg, M., \& MacMahon Ball, M. (2008). Providing transparency and credibility: the selection of international students for Australian universities. An examination of the relationship between scores in the International Student Admissions Test (ISAT), final year academic programs and an Australian university's foundation program. Higher Education Research \& Development, 27(4), 331-344. http://dx.doi.org/10.1080/07294360802406809

Marnewick, C. (2012). The Mystery of Student Selection: Are There Any Selection Criteria?, 38(2), 123-137. http://dx.doi.org/10.1080/03055698.2011.567041

Mattimore, P. (2008). University of California Should Keep Requiring SAT Subject Tests of Applicants. Chronicle of Higher Education, 54(47), A40.

McDermott, A. (2008). Surviving Without the SAT. Chronicle of Higher Education, 55(7), A41.

Morrison, M. C., \& Schmit, S. (2010). Predicting Success in a Gateway Mathematics Course. Retrieved from http://www.eric.ed.gov/ERICWebPortal/detail?accno=ED511033

Pandey, A. S., \& Dixit, H. M. (2011). Selection criteria and pre-clinical academic performance in a private medical college in Nepal: a case study. Med Teach, 33(4), e186-192. http://dx.doi.org/10.3109/0142159X.2011.546910

Pelech, W., Stalker, C. A., Regehr, C., \& Jacobs, M. (1999). Making the Grade: The Quest for 
Validity in Admissions Decisions. Journal of Social Work Education, 35(2), 215. http://dx.doi.org/10.1080/10437797.1999.10778961

Reibnegger, G., Caluba, H. C., Ithaler, D., Manhal, S., Neges, H. M., \& Smolle, J. (2010). Progress of medical students after open admission or admission based on knowledge tests. Med Educ, 44(2), 205-214. http://dx.doi.org/10.1111/j.1365-2923.2009.03576.x

Rich, A. M., Ayers, K. M., Thomson, W. M., Sinclair, R. J., Rohan, M. J., \& Seymour, G. J. (2012). Does performance in selection processes predict performance as a dental student? Eur J Dent Educ, 16(1), 27-34. http://dx.doi.org/10.1111/j.1600-0579.2011.00706.x

Salvatori, P. (2001). Reliability and validity of admissions tools used to select students for the health professions. Adv Health Sci Educ Theory Pract, 6(2), 159-175.

Saupe, J. L., \& Eimers, M. T. (2011). Correcting Correlations When Predicting Success in College. IR Applications, 31. Association for Institutional Research.

Schmitt, N. (2012). Development of Rationale and Measures of Noncognitive College Student Potential. Educational Psychologist, 47(1), 18-29. http://dx.doi.org/10.1080/ 00461520.2011 .610680

Schultz, S. J., \& Austin, H. W. (1987). An evaluation of a self-assessment test used to predict success in introductory college mathematics courses. International Journal of Mathematical Education in Science and Technology, 18(4), 507-518. http://dx.doi.org/10.1080/ 0020739870180402

Stemler, S. E. (2012). What Should University Admissions Tests Predict? Educational Psychologist, 47(1), 5-17. http://dx.doi.org/10.1080/00461520.2011.611444

Sternberg, R. J., Gabora, L., \& Bonney, C. R. (2012). Introduction to the Special Issue on College and University Admissions. Educational Psychologist, 47(1), 1-4. http://dx.doi.org/ 10.1080/00461520.2011.639652

Vargo, J. W., Madill, H. M., \& Davidson, P. R. (1986). The Pre-Admission Interview as a Predictor of Academic Grades and Fieldwork Performance. Canadian Journal of Occupational Therapy, 53(4), 211-215. http://dx.doi.org/10.1177/000841748605300406

Wenner, J. M., Burn, H. E., \& Baer, E. M. (2011). The Math You Need, when You Need It: Online Modules that Remediate Mathematical Skills in Introductory Geoscience Courses. Journal of College Science Teaching, 41(1), 16-24.

\section{Copyright Disclaimer}

Copyright reserved by the author(s).

This article is an open-access article distributed under the terms and conditions of the Creative Commons Attribution license (http://creativecommons.org/licenses/by/3.0/). 